\title{
Wearable Sensor-Based Biofeedback Training for Balance and Gait in Parkinson Disease: A Pilot Randomized Controlled Trial
}

\author{
Ilaria Carpinella, $\mathrm{MSc}^{,}{ }^{\mathrm{a}}$ Davide Cattaneo, $\mathrm{PhD},{ }^{\mathrm{b}}$ Gianluca Bonora, $\mathrm{PhD},{ }^{a}$ \\ Thomas Bowman, BSc, ${ }^{\mathrm{b}}$ Laura Martina, $\mathrm{MSc}^{\mathrm{b}}$ Angelo Montesano, MD, ${ }^{\mathrm{b}}$ \\ Maurizio Ferrarin, PhD $^{a}$
}

From the ${ }^{a}$ Biomedical Technology Department, and ${ }^{b}$ LaRiCE Lab, Department of Neurorehabilitation, Don Carlo Gnocchi Foundation, Milan, Italy.

\begin{abstract}
Objectives: To analyze the feasibility and efficacy of a novel system (Gamepad [GAMing Experience in PArkinson's Disease]) for biofeedback rehabilitation of balance and gait in Parkinson disease (PD).

Design: Randomized controlled trial.

Setting: Clinical rehabilitation gym.

Participants: Subjects with PD $(\mathrm{N}=42)$ were randomized into experimental and physiotherapy without biofeedback groups.

Interventions: Both groups underwent 20 sessions of training for balance and gait. The experimental group performed tailored functional tasks using Gamepad. The system, based on wearable inertial sensors, provided users with real-time visual and acoustic feedback about their movement during the exercises. The physiotherapy group underwent individually structured physiotherapy without feedback.

Main Outcome Measures: Assessments were performed by a blinded examiner preintervention, postintervention, and at 1-month follow-up. Primary outcomes were the Berg Balance Scale (BBS) and 10-m walk test (10MWT). Secondary outcomes included instrumental stabilometric indexes and the Tele-healthcare Satisfaction Questionnaire.

Results: Gamepad was well accepted by participants. Statistically significant between-group differences in BBS scores suggested better balance performances of the experimental group compared with the physiotherapy without biofeedback group both posttraining (experimental group - physiotherapy without biofeedback group: mean, $2.3 \pm 3.4$ points; $P=.047$ ) and at follow-up (experimental group-physiotherapy without biofeedback group: mean, $2.7 \pm 3.3$ points; $P=.018$ ). Posttraining stabilometric indexes showed that mediolateral body sway during upright stance was significantly reduced in the experimental group compared with the physiotherapy without biofeedback group (experimental group-physiotherapy without biofeedback group: $-1.6 \pm 1.5 \mathrm{~mm} ; P=.003$ ). No significant between-group differences were found in the other outcomes.

Conclusions: Gamepad-based training was feasible and superior to physiotherapy without feedback in improving BBS performance and retaining it for 1 month. After training, 10MWT data were comparable between groups. Further development of the system is warranted to allow the autonomous use of Gamepad outside clinical settings, to enhance gait improvements, and to increase transfer of training effects to real-life contexts.
\end{abstract}

Archives of Physical Medicine and Rehabilitation 2016

(c) 2016 by the American Congress of Rehabilitation Medicine

Supported by the Italian Ministry of Health (Ricerca Corrente and Ricerca Finalizzata: grant no. GR-2009-1604984).

The funding source had no involvement in study design, data collection, analysis and interpretation, writing of the report, and decision to submit the article for publication.

Clinical Trial Registration No.: NCT02713971.

Disclosures: none.
Balance and gait impairments are among the most disabling features of Parkinson disease (PD) and play a key role in the progressive deterioration of patients' autonomy. ${ }^{1}$ For this reason, motor rehabilitation is now considered essential in the treatment of $\mathrm{PD}$, as a complement to pharmacologic therapy and neurosurgery. ${ }^{1,2}$ 




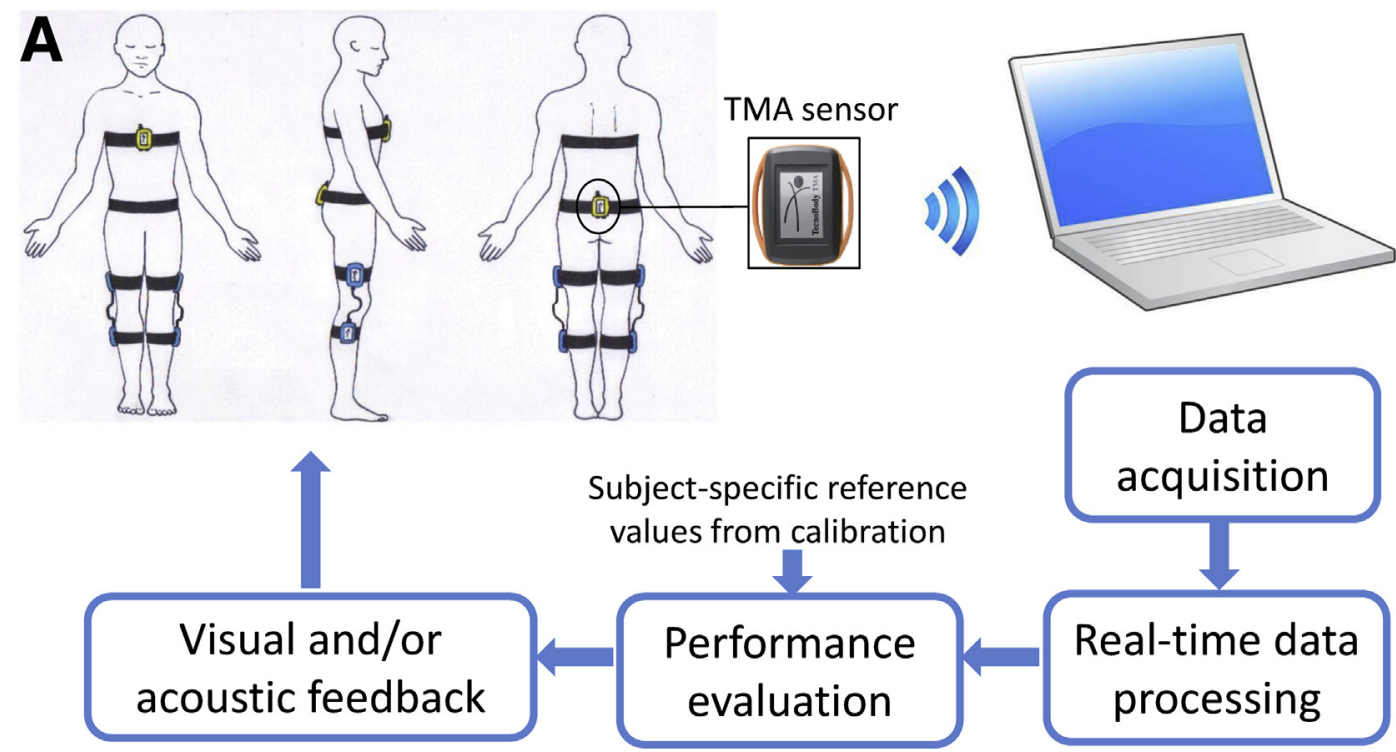

B
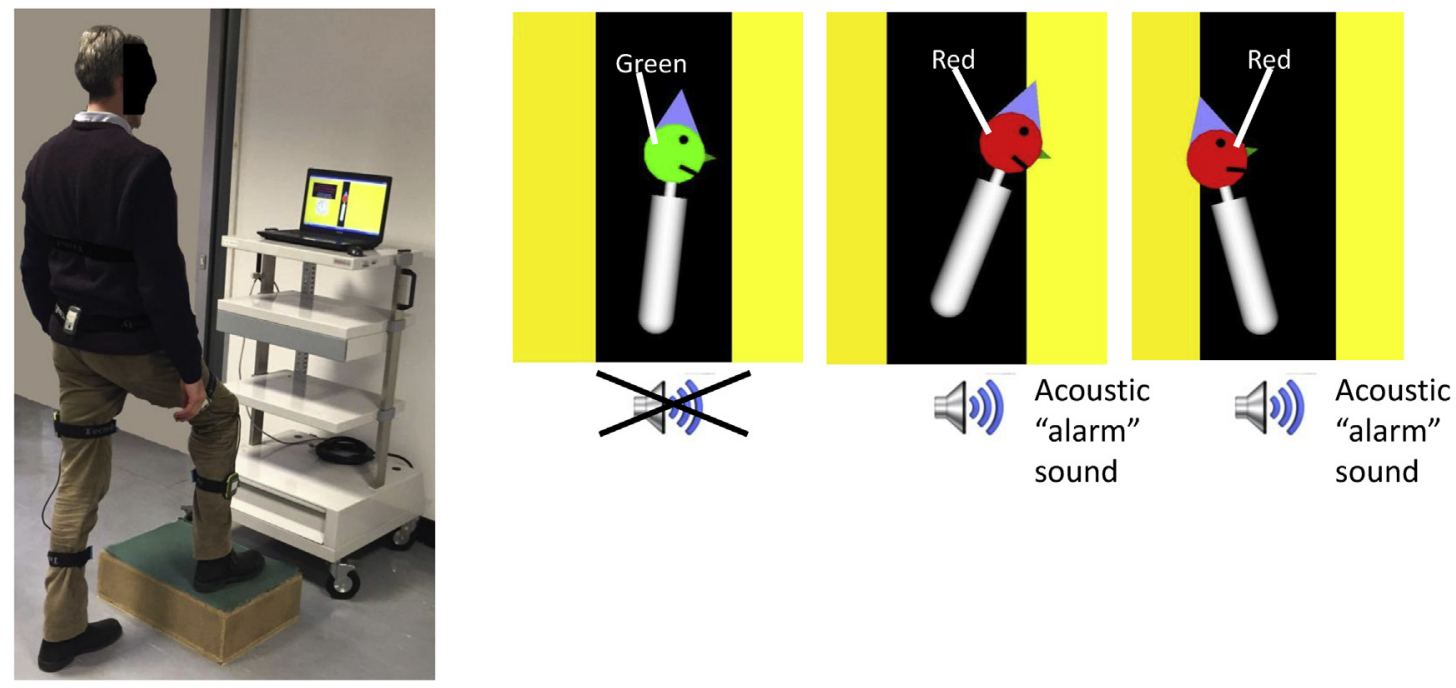

Fig 2 (A) Schematic representation of the Gamepad system. (B) Example of a subject controlling the AP inclination of his trunk while placing a foot on a step (left panel). The patient performs the task by looking at an avatar replicating the motion of his trunk on the PC screen (right panels). If the avatar is not maintained within the black bar (tailored reference target area), its head becomes red and an alarm sound is provided. Abbreviation: TMA sensor, Tecnobody Motion Analysis inertial sensor.

gradually reduces toward the end of treatment) was used to enhance learning. ${ }^{23}$

\section{Physiotherapy without biofeedback group}

Personalized exercises were defined by clinical staff following guidelines for physiotherapy in PD. ${ }^{2,21}$ Each session included 5 minutes of muscle stretching (hamstrings, quadriceps, and calves) and mobilization exercises (eg, trunk rotation, hip abduction, flexion), followed by 40 minutes of balance and gait exercises similar to those performed by the experimental group, but without any instrumentation producing biofeedback or external cues. Subjects executed the tasks following verbal instructions and qualitative feedback from the physiotherapist.

\section{Outcome measures}

Assessments were taken by a trained examiner, unaware of group assignment, at baseline (t0), posttraining (t1), and 1-month followup (t2). Assessments and treatments were conducted when participants were in the "on" phase of medication.

Primary outcomes were balance and self-selected gait speed, assessed, respectively, with the Berg Balance Scale (BBS) ${ }^{24-26}$ and $10-\mathrm{m}$ walk test (10MWT) ${ }^{26}$ Both tests are recommended tools for 
Table 1 Demographic and baseline clinical characteristics of training groups

\begin{tabular}{|c|c|c|}
\hline Characteristic & $\begin{array}{l}\text { Experimental } \\
\text { Group }(n=17)\end{array}$ & $\begin{array}{l}\text { Physiotherapy } \\
\text { Group }(n=20)\end{array}$ \\
\hline Sex (male/female) & $14 / 3$ & $9 / 11$ \\
\hline Age (y) & $73.0 \pm 7.1$ & $75.6 \pm 8.2$ \\
\hline Time since diagnosis $(y)$ & $7.5 \pm 3.2$ & $10.3 \pm 5.7$ \\
\hline$H-Y(0-5)^{*}$ & $2.7 \pm 0.7$ & $2.9 \pm 0.5$ \\
\hline BBS $(0-56)^{\dagger, \ddagger}$ & $46.0 \pm 9.3$ & $42.1 \pm 10.9$ \\
\hline 10MWT, gait speed $(\mathrm{m} / \mathrm{s})^{\ddagger \S}$ & $1.04 \pm 0.25$ & $0.78 \pm 0.29$ \\
\hline UPDRS-III $(0-56)^{*, \S}$ & $16.6 \pm 6.8$ & $22.3 \pm 7.3$ \\
\hline TUG $(s)^{*, \dagger, \delta}$ & $14.7 \pm 6.3$ & $23.9 \pm 16.3$ \\
\hline$A B C(0-100)^{\ddagger \S}$ & $59.3 \pm 21.8$ & $44.3 \pm 19.1$ \\
\hline FOGQ $(0-24)^{*}$ & $11.3 \pm 4.9$ & $13.1 \pm 3.8$ \\
\hline PDQ-39 $(0-100)^{*}$ & $46.4 \pm 22.9$ & $61.5 \pm 24.1$ \\
\hline CoP ML sway $(\mathrm{mm})^{*, \dagger}$ & $5.7 \pm 2.9$ & $6.7 \pm 3.5$ \\
\hline CoP AP sway $(\mathrm{mm})^{*, \dagger}$ & $7.7 \pm 3.4$ & $8.4 \pm 3.1$ \\
\hline
\end{tabular}

NOTE. Values are mean $\pm S D$ or number.

Abbreviations: ABC, Activities-specific Balance Confidence scale; FOGQ, Freezing of Gait Questionnaire; H-Y, Hoehn and Yahr stage; PDQ-39, Parkinson's Disease Questionnaire-39; TUG, timed Up and Go test.

* Lower scores indicate better performance.

$\dagger$ These variables did not meet assumptions of data normality and/or homogeneity of variances. In these cases, $t$ test was performed on transformed data (Box-Cox transformation).

¥ Higher scores indicate better performance.

$\S P<.05$ (experimental group vs physiotherapy group, $t$ test for independent samples).

\section{Statistical analysis}

Between-group comparisons of baseline characteristics were performed using independent samples $t$ tests. Differential effects of the 2 treatments were assessed using analysis of covariance with 1 between-group factor (group: experimental group or physiotherapy without biofeedback group) and 1 within-group factor (time: $\mathrm{t} 1$ or $\mathrm{t} 2$ ). For each outcome measure, the corresponding baseline score ( $\mathrm{t} 0$ ) was used as covariate. In this model, betweengroup differences (experimental group vs physiotherapy without biofeedback group) at postintervention and follow-up were used to assess treatment effect because the baseline score was used as the covariate, as reported by Norman and Streiner. ${ }^{34}$ After analysis of covariance, separate preplanned between-group comparisons at $\mathrm{t} 1$ and $\mathrm{t} 2$ were performed using independent samples $t$ tests, also correcting for t0 score (contrasts analysis). Given the exploratory nature of this pilot study, the significance level was set to .05, and no corrections for multiple comparisons were applied. Betweengroup differences and effect sizes (Cohen $d)^{35}$ at $\mathrm{t} 1$ and $\mathrm{t} 2$ were also computed. Cohen $d$ of $0.2,0.5$, and 0.8 represents small, moderate, and large effect sizes, respectively. ${ }^{35}$ Some variables did not meet the assumptions of data normality and/or homogeneity of variances (Shapiro-Wilk test and/or Levene test, $P<.05$ ). In these cases, statistical tests were applied on transformed data (Box-Cox transformation). ${ }^{36}$ Where explicitly indicated, results were presented as estimated from back-transformed data, ${ }^{37}$ to facilitate interpretation. Statistical analysis was performed using STATISTICA. $^{\text {d }}$

\section{Results}

Twenty-two participants were allocated to the experimental group, and 20 were allocated to the physiotherapy without biofeedback group (see fig 1). Five patients discontinued the training, and 5 were lost at follow-up. Dropout reasons (see fig 1) were unrelated to the study. All patients who received allocated treatment and underwent posttraining assessment were analyzed (experimental group: $n=17$, physiotherapy without biofeedback group: $n=20$ ). Missing follow-up values (5 subjects $\times 9$ variables) were estimated using multiple regression. ${ }^{38}$ For each outcome measure, the predictors were the corresponding pre- and posttreatment scores, age, disease duration, Hoehn and Yahr stage, and UPDRS-III baseline score. Table 1 shows the baseline characteristics of analyzed participants. The physiotherapy without biofeedback group showed statistically significant worse scores on the 10MWT, UPDRS-III, timed Up and Go test, and Activitiesspecific Balance Confidence scale. The 5 subjects who discontinued the training were excluded because they underwent $<10$ sessions. Baseline characteristics of these patients were comparable with those of analyzed experimental group participants $(P \geq .150)$

\section{Primary outcomes}

Table 2 reports between-group comparisons at $\mathrm{t} 1$ and $\mathrm{t} 2$. Analysis of covariance revealed a significant effect of group in BBS score $\left(\mathrm{F}_{1,34}=6.29 ; P=.017\right)$, showing better balance performances of the experimental group compared with physiotherapy without biofeedback group both at posttreatment (experimental group-physiotherapy without biofeedback group: mean, $2.3 \pm 3.4$ points; $P=.047$, Cohen $d=.68$ ) and follow-up (experimental 
Outcomes characterizing the EG and CG at postintervention and follow-up

\begin{tabular}{|c|c|c|c|c|c|c|c|c|c|c|}
\hline \multirow[b]{2}{*}{ Outcome Measure } & \multicolumn{5}{|c|}{ Posttreatment (t1) } & \multicolumn{5}{|c|}{ 1-mo Follow-Up (t2) } \\
\hline & $\begin{array}{l}E G(n=17) \\
\text { Mean } \pm S D\end{array}$ & $\begin{array}{l}\text { CG }(n=20), \\
\text { Mean } \pm \text { SD }\end{array}$ & $\begin{array}{l}\text { Between-Group } \\
\text { Difference } \\
\text { (EG-CG), }{ }^{*} \\
\text { Mean } \pm \text { SE }\end{array}$ & $P$ & $\begin{array}{c}\text { Cohen } d \\
\text { Mean }(95 \% \mathrm{CI})\end{array}$ & $\begin{array}{l}\text { EG }(n=17) \\
\text { Mean } \pm \text { SD }\end{array}$ & $\begin{array}{l}\text { CG }(n=20), \\
\text { Mean } \pm \text { SD }\end{array}$ & $\begin{array}{l}\text { Between-Group } \\
\text { Difference } \\
\text { (EG-CG), } \\
\text { Mean } \pm \text { SE }\end{array}$ & $P$ & $\begin{array}{c}\text { Cohen } d \\
\text { Mean (95\% CI) }\end{array}$ \\
\hline \multicolumn{11}{|l|}{ Primary } \\
\hline BBS $(0-56)^{\dagger, \ddagger}$ & $50.0 \pm 6.2$ & $43.8 \pm 10.9$ & $2.3 \pm 1.1$ & $.047^{\S}$ & $0.68(0.02$ to 1.34$)$ & $48.1 \pm 10.7$ & $42.3 \pm 11.5$ & $2.7 \pm 1.1$ & $.018^{\S}$ & $0.82(0.15$ to 1.49$)$ \\
\hline $\begin{array}{l}\text { 10MWT, gait speed } \\
(\mathrm{m} / \mathrm{s})^{\ddagger}\end{array}$ & $1.17 \pm 0.23$ & $0.87 \pm 0.33$ & $0.06 \pm 0.06$ & .335 & $0.32(-0.33$ to 0.97$)$ & $1.17 \pm 0.29$ & $0.87 \pm 0.33$ & $0.05 \pm 0.06$ & .395 & $0.28(-0.37$ to 0.93$)$ \\
\hline \multicolumn{11}{|l|}{ Secondary } \\
\hline UPDRS-III $(0-56)^{\|}$ & $13.6 \pm 6.8$ & $19.1 \pm 7.9$ & $-1.1 \pm 1.8$ & .545 & $-0.20(-0.85$ to 0.45$)$ & $16.2 \pm 7.1$ & $18.2 \pm 6.9$ & $2.2 \pm 1.7$ & .196 & $0.43(-0.22$ to 1.08$)$ \\
\hline TUG $(s)^{\dagger, \|}$ & $13.7 \pm 5.6$ & $24.3 \pm 18.0$ & $-1.8 \pm 1.6$ & .269 & $-0.37(-1.02$ to 0.28$)$ & $13.4 \pm 6.5$ & $20.2 \pm 12.0$ & $-1.2 \pm 1.4$ & .380 & $-0.29(-0.94$ to 0.36$)$ \\
\hline$A B C(0-100)^{\ddagger}$ & $67.2 \pm 22.3$ & $47.8 \pm 22.2$ & $7.6 \pm 5.6$ & .186 & $0.45(-0.20$ to 1.10$)$ & $60.6 \pm 22.7$ & $45.3 \pm 19.2$ & $2.3 \pm 4.1$ & .580 & $0.18(-0.47$ to 0.83$)$ \\
\hline FOGQ $(0-24)^{\|}$ & $10.8 \pm 5.1$ & $12.5 \pm 3.9$ & $-0.4 \pm 1.1$ & .695 & $-0.13(-0.78$ to 0.52$)$ & $11.1 \pm 4.9$ & $12.6 \pm 4.3$ & $0.06 \pm 0.9$ & .947 & $0.02(-0.63$ to 0.67$)$ \\
\hline PDQ-39 $(0-100)^{\|}$ & $44.6 \pm 24.7$ & $59.2 \pm 23.3$ & $-0.7 \pm 3.7$ & .844 & $-0.07(-0.71$ to 0.58$)$ & $48.4 \pm 27.2$ & $56.8 \pm 22.4$ & $5.0 \pm 4.7$ & .285 & $0.36(-0.29$ to 1.01$)$ \\
\hline CoP ML sway $(m m)^{\dagger, \|}$ & $4.8 \pm 2.7$ & $6.7 \pm 2.1$ & $-1.6 \pm 0.5$ & $.003^{\S}$ & $-1.06(-1.75$ to -0.37$)$ & $6.3 \pm 4.1$ & $7.8 \pm 4.3$ & $-0.7 \pm 0.7$ & .306 & $-0.34(-0.99$ to 0.31$)$ \\
\hline CoP AP sway $(\mathrm{mm})^{\dagger, \|}$ & $7.1 \pm 3.2$ & $8.8 \pm 3.2$ & $-1.2 \pm 0.6$ & .075 & $-0.61(-1.27$ to 0.05$)$ & $7.6 \pm 3.9$ & $8.5 \pm 3.0$ & $-0.7 \pm 0.8$ & .359 & $-0.31(-0.96$ to 0.34$)$ \\
\hline
\end{tabular}

Abbreviations: ABC, Activities-specific Balance Confidence scale; CG, physiotherapy group; CI, confidence interval; EG, experimental group; F0GQ, Freezing of Gait Questionnaire; PDQ-39, Parkinson's Disease Questionnaire-39; TUG, timed Up and Go test.

* Adjusted for pretreatment score (to) by analysis of covariance.

These variables did not meet assumptions of data normality and/or homogeneity of variances. In this cases, statistical tests and Cohen $d$ computation were performed on transformed data (Box-Cox transformation). Reported between-group differences were estimated from back-transformed results to facilitate interpretation.

* Higher scores indicate better performance.

$\S<$.05 (EG vs CG, contrast analysis using independent sample $t$ test).

" Lower scores indicate better performance. 
Table 3 Descriptive statistics of the Tele-healthcare Satisfaction Questionnaire-Wearable Technology for benefit, usability, and wearing comfort of the Gamepad system

\begin{tabular}{|c|c|}
\hline Area and Statement & Value \\
\hline \multicolumn{2}{|l|}{ Benefit } \\
\hline 1. I can benefit from this technology & $3(1-4)$ \\
\hline 2. The effort of using this technology/method is worthwhile for me & $4(2-4)$ \\
\hline 3. I am confident I am getting the most out of this technology/method & $4(1-4)$ \\
\hline 4. This technology/method is helping me to achieve my goals & $3(1-4)$ \\
\hline 5. I would recommend this technology/method to other people in my situation & $4(1-4)$ \\
\hline \multicolumn{2}{|l|}{ Usability } \\
\hline 6. The use of this technology/method requires effort & $3(0-4)$ \\
\hline 7. The technology/method is reliable according to my estimation and experience so far & $3(2-4)$ \\
\hline 8. This technology/method is easy to use & $4(2-4)$ \\
\hline 9. I feel safe when using this technology/method & $3(2-4)$ \\
\hline 10. I feel good while using this technology/method & $3(1-4)$ \\
\hline \multicolumn{2}{|l|}{ Wearing comfort } \\
\hline 11. Wearing this device (parts of the device) is comfortable & $4(1-4)$ \\
\hline 12. I am pleased with the size of the device (parts of the device) & $4(2-4)$ \\
\hline 13. I would wish for another look and design of the device (parts of the device) & $1(0-2)$ \\
\hline 14. I am pleased with the weight of the device (parts of the device) & $3(2-4)$ \\
\hline 15. The body-worn parts of the device are difficult to adjust (fix, fasten) & $1(0-3)$ \\
\hline
\end{tabular}

NOTE. Values represent median (minimum-maximum) score given by patients to each statement on a 5-point Likert scale (where 0 is strongly disagree, 1 is mostly disagree, 2 is neither agree nor disagree, 3 is mostly agree, and 4 is strongly agree).

group-physiotherapy without biofeedback group: mean, $2.7 \pm 3.3$ points; $P=.018 ; d=.82$ ). No significant group or time $\times$ group effects were found in the 10MWT; however, a small effect size favoring the experimental group was present ( $\mathrm{t} 1: d=.32 ; \mathrm{t} 2: d=.28$ ).

\section{Secondary outcomes}

Analysis of covariance (see table 2) revealed a significant effect of group $\left(\mathrm{F}_{1,34}=6.12 ; P=.018\right)$ in CoP ML sway, which was significantly smaller in the experimental group than the physiotherapy without biofeedback group at 11 (experimental group-physiotherapy without biofeedback group: $-1.6 \pm 1.5 \mathrm{~mm} ; P=.003 ; d=-1.06$ ), but not at $\mathrm{t} 2$ (experimental group-physiotherapy without biofeedback group: $-0.7 \pm 2.1 \mathrm{~mm} ; P=.306 ; d=-.34$ ). No significant group or time $\times$ group effects were found in the UPDRS-III, timed Up and Go test, Activities-specific Balance Confidence scale, Freezing of Gait Questionnaire, Parkinson's Disease Questionnaire-39, and AP sway.

The Tele-healthcare Satisfaction Questionnaire-Wearable Technology (table 3 ) showed that all patients but one (statement 1 score: 1) found the device beneficial (statement 1 score: 3-4). Gamepad was considered reliable, easy to use, and safe by all patients (statements 7-9 scores: 2-4) and comfortable by 15 out of 17 subjects (statement 11 score: $2-4$ ). Of patients, $65 \%$ found that using Gamepad required effort (statement 6 score: $3-4$ ) and that such effort was worthwhile for them (statement 2 score: $2-4$ ).

Physiotherapists were positive about Gamepad training, but they suggested to reduce the number of sensors and simplify the procedures for task calibration.

\section{Discussion}

In this study, a new system for biofeedback motor rehabilitation in PD (Gamepad) was developed and clinically applied in a pilot randomized controlled trial to test its feasibility and efficacy compared with physiotherapy without feedback. Compared with existing devices, to our knowledge, this is the first wearable system integrating both balance and gait tailored exercises similar to activities of daily living.

Between-group comparisons through analysis of covariance showed statistically significant higher scores on the BBS in the experimental group than the physiotherapy without biofeedback group at $\mathrm{t} 1$ ( 2.3 points) and $\mathrm{t} 2$ ( 2.7 points). These differences were in the range of those emerged in other studies using the BBS to compare physiotherapy methods (mean, 2.79; 95\% confidence interval, 0.50-5.08), ${ }^{39}$ highlighting the positive affect of the proposed intervention on balance performance in PD. Moreover, the mean posttraining increase in the BBS score by 4.0 points in the experimental group and 1.7 points in the physiotherapy without biofeedback group suggested that only the mean improvement of the experimental group was consistent with the minimal detectable change between 2.8 and 5 points found in previous studies on PD. ${ }^{25,26}$ Noteworthy, no between-group differences were found in studies using biofeedback systems based on balance boards, ${ }^{8,9}$ suggesting higher efficacy of wearable devices that allow the execution of more ecologic tasks.

This result is enforced by instrumental indexes describing static balance in different sensory conditions. In particular, the amplitude of CoP ML sway at posttraining was lower in the experimental group than the physiotherapy without biofeedback group, with a statistically significant large effect size favoring the experimental group $(d=-1.06)$. This finding is particularly notable because ML sway amplitude (significantly increased in PD) ${ }^{32}$ was found to be the best stabilometric parameter predicting future falls. ${ }^{40}$ Although this improvement was not maintained at follow-up, this result corroborated previous studies ${ }^{7,14}$ and suggested beneficial effects of biofeedback in increasing balance control in altered sensory conditions, which strongly affect postural stability in PD. ${ }^{32}$ 
Taken together, these findings about the BBS and ML body sway seemed to support the hypothesis that Gamepad-based training is superior to physiotherapy without feedback in improving balance in PD and increasing retention of some beneficial effects in the short term (1mo). As suggested by Nieuwboer et $a{ }^{5}{ }^{5}$ the present findings can be ascribed to the contribution of biofeedback in enhancing motor learning, which is feasible in PD although impaired. ${ }^{1}$ In particular, provision of additional sensory information could have helped patients not only during the first (cognitive) stage of learning, by focalizing their attention toward the task, ${ }^{2,5}$ but also during the last (automatization) stage, as suggested by follow-up BBS scores showing higher retention in the Gamepad group. ${ }^{5}$ In this context, a second possible explanation about the greater benefits attained by the experimental group could be related to the better baseline characteristics compared with the physiotherapy without biofeedback group, which can be potentially associated with higher learning abilities. ${ }^{1}$ However, we think that this hypothesis can be excluded given the lack of correlation (see supplemental appendix S3, available online only at http://www.archives-pmr. org/) between change scores in the BBS and age, disease duration, and severity level (Hoehn and Yahr stage and UPDRS-III), suggesting that balance improvements were independent from these factors. Moreover, statistical analysis was conducted by adjusting for baseline scores.

Contrary to balance, no significant between-group differences emerged in walking speed and Freezing of Gait Questionnaire. Hence, our findings did not support the hypothesis that Gamepadbased training is superior to physiotherapy without biofeedback in improving gait in PD. This could be because of not only the need of a personal computer that restricted the use of Gamepad to rehabilitation gyms, but also to the training paradigms, which included tasks for the control of trunk posture and body-weight shifting during locomotion, but not exercises specifically devoted to the biofeedback-based regulation of spatiotemporal gait parameters typically impaired in $\mathrm{PD}^{2}$ (eg, velocity, cadence, stride length), or to the reduction of freezing episodes. ${ }^{11,13}$

Finally, no significant between-group differences were found in the Parkinson's Disease Questionnaire-39 and Activitiesspecific Balance Confidence scale, suggesting that the beneficial effects of Gamepad training did not increase perceived quality of life and confidence in activities of daily living compared with physiotherapy without biofeedback. Although the rehabilitation paradigms implemented within Gamepad followed a functional approach, ${ }^{2,4}$ these findings seemed to confirm previous results about limited transfer of training effects to activities of daily living and quality of life. ${ }^{5,11}$ This also suggested further developments of Gamepad to extend its use outside clinical settings, making the training environment as close as possible to real-life contexts. ${ }^{5,13}$

\section{Study limitations}

This study had some limitations. First, the small sample size underpowered the study. A power analysis on posttreatment BBS scores revealed that 70 subjects (35 per group) are required to achieve a between-group effect size of .68 , given $\alpha=.05$ and $1-\beta=0.8$. Besides, the analysis of posttraining 10MWT scores showed that 152 patients per group are necessary to achieve an effect size of .32 with the same values of $\alpha$ and $\beta$. A second limitation is the randomization procedure used for patients' allocation, which resulted in unbalanced baseline characteristics between the 2 groups. Alternative methods (eg, block or stratified randomization), more suitable for small trials, would have reduced the occurrence of such unbalancing. ${ }^{18}$ A third limitation is that the placebo effect resulting from increased motivation was not controlled for during Gamepad training. Application of sensors, without biofeedback, to the physiotherapy without biofeedback group would have acted as a sham-device, also providing objective measures of motor performances. Finally, some technical aspects of Gamepad should be further developed in future studies to improve system portability and gain more meaningful improvement in gait (eg, reduction of sensors, replacement of a personal computer with a wearable processing unit [eg, smartphone], ${ }^{6,13}$ implementation of algorithms allowing online computation of spatiotemporal gait parameters to be used as biofeedback variables and objective measures of locomotion). ${ }^{10,13}$

\section{Conclusions}

Gamepad was proven feasible for clinical use on subjects with PD, was generally well-accepted by patients and physiotherapists, and seemed more effective than physiotherapy without biofeedback in improving balance. Future studies should be performed to include more sophisticated rehabilitation paradigms for gait training ${ }^{10,13}$ and to realize a simplified, completely wearable system, potentially usable by patients in autonomy also outside hospital (eg, at home), to enhance the improvements, to prolong their retention, and to increase transfer of training effects to real-life contexts.

\section{Suppliers}
a. TecnoBody.
b. .NET; Microsoft.
c. MATLAB/Simulink; MathWorks.
d. STATISTICA; StatSoft.

\section{Keywords}

Gait; Parkinson disease; Postural balance; Rehabilitation

\section{Corresponding author}

Davide Cattaneo, PhD, Larice Lab, Department of Neurorehabilitation, Don Carlo Gnocchi Foundation, Via Cepecelatro 66, 20148 Milan, Italy. E-mail address: dcattaneo@ dongnocchi.it.

\section{References}

1. Abbruzzese G, Marchese R, Avanzino L, Pelosin E. Rehabilitation for Parkinson's disease: current outlook and future challenges. Park Relat Disord 2016;(22 Suppl 1):S60-4.

2. Morris ME. Movement disorders in people with Parkinson disease: a model for physical therapy. Phys Ther 2000;80:578-97.

3. Tomlinson CL, Herd CP, Clarke CE, et al. Physiotherapy for Parkinson's disease: a comparison of techniques. Cochrane Database Syst Rev 2014;6:CD002815.

4. Huang H, Wolf SL, He J. Recent developments in biofeedback for neuromotor rehabilitation. J Neuroeng Rehabil 2006;3:11. 
5. Nieuwboer A, Rochester L, Müncks L, Swinnen SP. Motor learning in Parkinson's disease: limitations and potential for rehabilitation. Park Relat Disord 2009;(15 Suppl 3):S53-8.

6. Casamassima F, Ferrari A, Milosevic B, Ginis P, Farella E, Rocchi L. A wearable system for gait training in subjects with Parkinson's disease. Sensors (Basel) 2014;14:6229-46.

7. Yen CY, Lin KH, Hu MH, Wu RM, Lu TW, Lin CH. Effects of virtual reality-augmented balance training on sensory organization and attentional demand for postural control in people with Parkinson disease: a randomized controlled trial. Phys Ther 2011;91:862-74.

8. van den Heuvel MR, Kwakkel G, Beek PJ, Berendse HW, Daffertshofer A, van Wegen EE. Effects of augmented visual feedback during balance training in Parkinson's disease: a pilot randomized clinical trial. Park Relat Disord 2014;20:1352-8.

9. Yang WC, Wang HK, Wu RM, Lo CS, Lin KH. Home-based virtual reality balance training and conventional balance training in Parkinson's disease: a randomized controlled trial. J Formos Med Assoc 2016;115:734-43.

10. Espay AJ, Baram Y, Dwivedi AK, et al. At-home training with closedloop augmented-reality cueing device for improving gait in patients with Parkinson disease. J Rehabil Res Dev 2010;57:573-81.

11. Nieuwboer A, Kwakkel G, Rochester L, et al. Cueing training in the home improves gait-related mobility in Parkinson's disease: the RESCUE trial. J Neurol Neurosurg Psychiatry 2007;78:134-40.

12. Mirelman A, Herman T, Nicolai S, et al. Audio-biofeedback training for posture and balance in patients with Parkinson's disease. J Neuroeng Rehabil 2011;8:35.

13. Ginis P, Nieuwboer A, Dorfman M, et al. Feasibility and effects of home-based smartphone-delivered automated feedback training for gait in people with Parkinson's disease: a pilot randomized controlled trial. Park Relat Disord 2016;22:28-34.

14. Rossi-Izquierdo M, Ernst A, Soto-Varela A, et al. Vibrotactile neurofeedback balance training in patients with Parkinson's disease: reducing the number of falls. Gait Posture 2013;37:195-200.

15. Lee BC, Thrasher TA, Fisher SP, Layne CS. The effects of different sensory augmentation on weight-shifting balance exercises in Parkinson's disease and healthy elderly people: a proof-of-concept study. J Neuroeng Rehabil 2015;12:75.

16. Caudron S, Guerraz M, Eusebio A, Gros JP, Azulay JP, Vaugoyeau M. Evaluation of a visual biofeedback on the postural control in Parkinson's disease. Neurophysiol Clin 2014;44:77-86.

17. Pfeiffer E. A short portable mental status questionnaire for the assessment of organic brain deficit in elderly patients. J Am Geriatr Soc 1975;23:433-41.

18. Vickers AJ. How to randomize. J Soc Integr Oncol 2006;4:194-8.

19. Smania N, Corato E, Tinazzi M, et al. Effect of balance training on postural instability in patients with idiopathic Parkinson's disease. Neurorehabil Neural Repair 2010;24:826-34.

20. Bonora G, Carpinella I, Cattaneo D, Chiari L, Ferrarin M. A new instrumented method for the evaluation of gait initiation and step climbing based on inertial sensors: a pilot application in Parkinson's disease. J Neuroeng Rehabil 2015;12:45.

21. Keus SH, Bloem BR, Hendriks EJ, Bredero-Cohen AB, Munneke M. Evidence-based analysis of physical therapy in Parkinson's disease with recommendations for practice and research. Mov Disord 2007; 22:451-60.
22. Bagalà F, Fuschillo VL, Chiari L, Cappello A. Calibrated 2D angular kinematics by single-axis accelerometers: from inverted pendulum to N-link chain. IEEE Sens J 2012;12:479-86.

23. Winstein CJ, Schmidt RA. Reduced frequency of knowledge of results enhances motor skill learning. J Exp Psychol Learn Mem Cogn 1990; 16:677-91.

24. Berg KO, Wood-Dauphinee SL, Williams JI, Gayton D. Measuring balance in the elderly: preliminary development of an instrument. Physiother Can 1989;41:304-11.

25. Lim LI, van Wegen EE, de Goede CJ, et al. Measuring gait and gaitrelated activities in Parkinson's patients own home environment: a reliability, responsiveness and feasibility study. Park Relat Disord 2005;11:19-24.

26. Steffen T, Seney M. Test-retest reliability and minimal detectable change on balance and ambulation tests, the 36-item short-form health survey, and the unified Parkinson disease rating scale in people with parkinsonism. Phys Ther 2008;88:733-46.

27. Bloem BR, Marinus J, Almeida Q, et al. Measurement instruments to assess posture, gait, and balance in Parkinson's disease: critique and recommendations. Mov Disord 2016;31:1342-55.

28. Paker N, Bugdayci D, Goksenoglu G, Demircioğlu DT, Kesiktas N, Ince N. Gait speed and related factors in Parkinson's disease. J Phys Ther Sci 2015;27:3675-9.

29. Fahn SE; UPDRS Development Committee. Unified Parkinson's Disease Rating Scale. In: Fahn S, Marsden CD, Calne DB, Goldstein M, editors. Recent developments in Parkinson's disease. 2nd ed. Florham Park: Macmillan; 1987. p 153-63.

30. Giladi N, Shabtai H, Simon ES, Biran S, Tal J, Korczyn AD. Construction of freezing of gait questionnaire for patients with Parkinsonism. Park Relat Disord 2000;6:165-70.

31. Fitzpatrick R, Peto V, Jenkinson C, Greenhall R, Hyman N. Healthrelated quality of life in Parkinson's disease: a study of outpatient clinic attenders. Mov Disord 1997;12:916-22.

32. Cattaneo D, Carpinella I, Aprile I, Prosperini L, Montesano A, Jonsdottir J. Comparison of upright balance in stroke, Parkinson and multiple sclerosis. Acta Neurol Scand 2016;133:346-54.

33. Ambrosini E, Ferrante S, Rossini M, et al. Functional and usability assessment of a robotic exoskeleton arm to support activities of daily life. Robotica 2014;32:1213-24.

34. Norman GR, Streiner DL. Biostatistics: the bare essentials. 3rd ed. Hamilton: BC Decker; 2007.

35. Cohen J. Statistical power analysis. Curr Dir Psychol Sci 1992;1: 98-101.

36. Box GE, Cox DR. An analysis of transformations. J R Stat Soc Series B Methodol 1964;26:211-52.

37. Jørgensen E, Pedersen AR. How to obtain those nasty standard errors from transformed data - and why they should not be used. Aarhus Univ Det Jordbrugsvidenskabelige Fak 1998;7:1-20.

38. Streiner DL, Norman GR. Missing data. Community Oncol 2010;7: 429-31.

39. Tomlinson CL, Patel S, Meek C, et al. Physiotherapy versus placebo or no intervention in Parkinson's disease. Cochrane Database Syst Rev 2013;9:CD002817.

40. Maki BE, Holliday PJ, Topper AK. A prospective study of postural balance and risk of falling in an ambulatory and independent elderly population. J Gerontol 1994;49:M72-84. 


\section{Supplemental Appendix S1 Examples of Tasks Included Within the Gamepad System}

\section{Static}

\section{Task}

Upright standing by controlling the knee flexion and the ML (or AP) inclination of the trunk.

\section{Instruction and feedback}

The patient is asked to maintain upright balance trying to keep the knee extended and to control the ML (or AP) inclination of upper trunk. A visual feedback is provided about knee flexion/extension angle, represented by a vertical bar on the monitor (supplemental fig S1). If knee extension is below a threshold defined by the physiotherapist, the bar is red, otherwise, if the patient maintains a correct extension, the bar turns green. Simultaneously, an auditory feedback is provided about ML (or AP) trunk inclination. If this variable is within a tailored reference band defined by the therapist, no sound is provided, otherwise Gamepad produces alarm sounds (negative feedback): high-pitch sound in case of excessive right (or forward) inclination, low-pitch sound in case of excessive left (or backward) inclination.
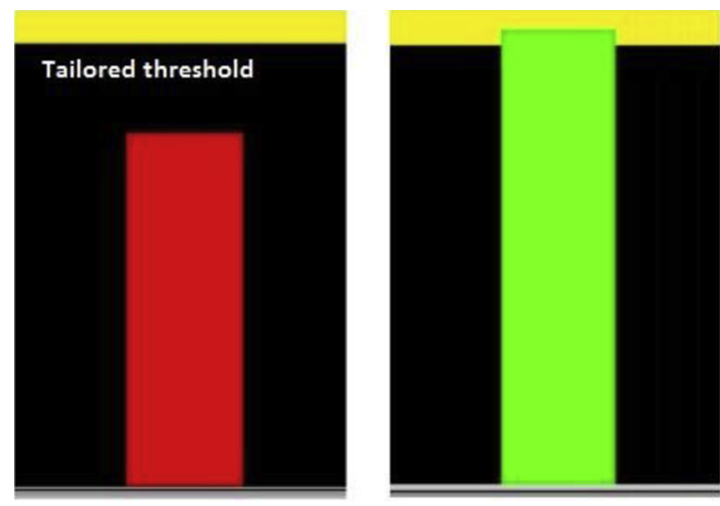

Supplemental Fig S1 Example of visual feedback provided by Gamepad. The vertical bar represents the knee flexion/extension angle. The bar is red in case of excessive knee flexion (left panel), whereas it turns green in case of adequate knee extension (right panel).
Note that the exercise can be performed on firm surface or with foam pad under feet.

\section{Quasi-dynamic}

\section{Task}

Place a foot on a step after a correct shift of body weight toward the supporting limb.

\section{Instruction and biofeedback}

The subject is asked to transfer the body weight toward the supporting leg, keep this position for a time defined by the therapist, and then place the opposite foot on a step placed in front of him. The patient performs the task by looking at a circle replicating the motion of the center of mass on the computer screen (supplemental fig S2). The circle has to be moved from a starting position (white rectangle) toward a yellow target area, whose position and dimensions are defined by the therapist based on subjects' ability. If the circle is kept within the target area, its color is green, otherwise it turns red and an alarm sound is provided (negative feedback). After a given time, the patient places the leading foot on the step.

\section{Dynamic}

\section{Task}

Straight-line walking controlling the transfer of body weight between limbs.

\section{Instruction and feedback}

The subject is asked to walk while controlling the ML shift of body weight, estimated with the ML angular displacement of the lower trunk. ${ }^{15}$ If this variable is above a tailored threshold, indicating the correct transfer of body weight toward the stance limb, Gamepad provides a sound (positive feedback).

\section{Task}

Walking over obstacles controlling the ML (or AP) inclination of the upper trunk.

\section{Instruction and feedback}

The subject is asked to walk over wooden sticks placed on the floor, maintaining the ML (or AP) inclination of the trunk within a

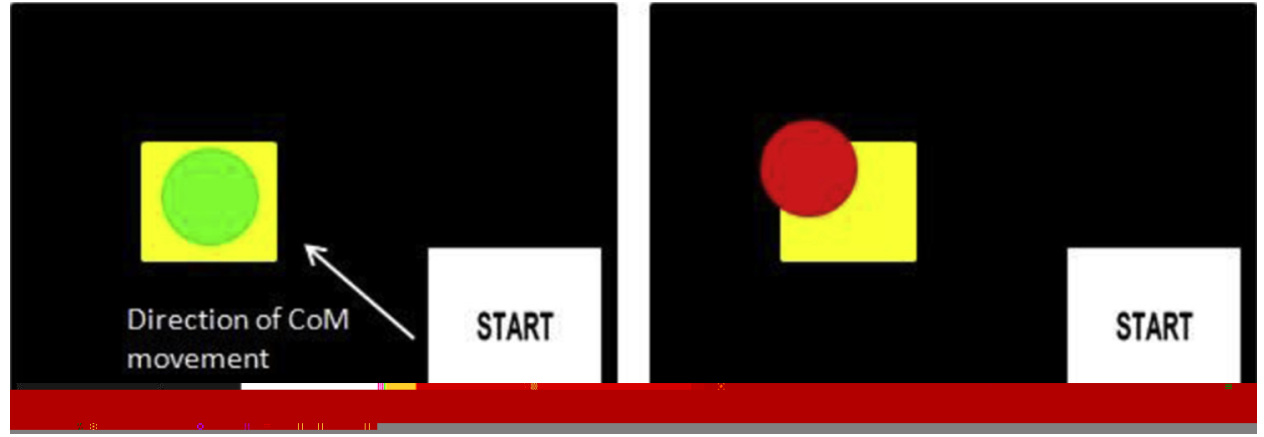

Supplemental Fig S2 Example of visual feedback provided by Gamepad. The circle represents the CoM that has to be moved from a starting position (START rectangle) to a final target position (yellow rectangle) toward the left (supporting) leg. The circle is green if the CoM in maintained within the target area, otherwise it turns red. Abbreviation: CoM, center of mass. 
reference band defined by the therapist. If trunk inclination is outside the target band, Gamepad provides alarm sounds (negative feedback): high-pitch sound in case of excessive right (or forward) inclination, and low-pitch sound in case of excessive left (or backward) inclination.

Note that the exercise can be executed at a self-selected velocity or at a fast speed, as indicated by the physiotherapist.

\section{Supplemental Appendix S2 Brief Description of the Outcome Measures}

\section{Primary outcomes}

\section{Berg Balance Scale}

The $\mathrm{BBS}^{24-26}$ rates balance from 0 (cannot perform) to 4 (normative performance) on 14 items exploring the ability to sit, stand, lean, turn, and maintain the upright position on 1 leg. Maximum score (ie, 56 points) indicates unimpaired balance.

\section{0-m walk test}

The $10 \mathrm{MWT}^{26}$ measures, with a stopwatch, the time $(T)$ taken by the subject to walk between 2 lines at the distance of $10 \mathrm{~m}$. Walking speed is therefore computed as $10 / T(\mathrm{~m} / \mathrm{s})$. Both comfortable and fast gait speed can be measured. In this study only comfortable gait speed was assessed.

\section{Secondary outcomes}

\section{Unified Parkinson's Disease Rating Scale}

The Unified Parkinson's Disease Rating Scale ${ }^{29}$ is the criterion standard instrument used to measure disease severity and diseasespecific impairments in PD. It has 3 subscales: I (Mentation, Behavior, and Mood), II (Activities of Daily Living); and III (Motor Examination). Each item is rated on a 5-point ordinal scale from 0 to 4 , with 4 representing the greatest level of dysfunction. In this study, only UPDRS-III was administered.

\section{Timed Up and Go test}

The timed Up and Go test ${ }^{26}$ is a mobility test evaluating the time taken by the subject to rise from a chair, walk $3 \mathrm{~m}$, turn around, walk back to the chair, and sit down.

\section{Activities-specific Balance Confidence scale}

The Activities-specific Balance Confidence scale ${ }^{26}$ is a questionnaire through which the subject rates his/her perceived level of confidence while performing 16 daily living activities. Scores range from $0 \%$ (not confident) to $100 \%$ (completely confident).

\section{Freezing of Gait Questionnaire}

The Freezing of Gait Questionnaire ${ }^{30}$ evaluates freezing severity with a 6-item interview. Each item is rated on a 5-point ordinal scale from 0 (absence of freezing) to 4 (severe freezing).

\section{Parkinson's Disease Questionnaire-39}

The Parkinson's Disease Questionnaire-39 is a 39-item, self-report questionnaire, ${ }^{31}$ which assesses PD-specific health-related quality of life over the last month. Scores are from 0 to 100, with 100 representing the maximum level of problems.

\section{Tele-healthcare Satisfaction Questionnaire- Wearable Technology}

The Tele-healthcare Satisfaction Questionnaire-Wearable Technology ${ }^{33}$ consists of 6 areas (benefit, usability, self-concept, privacy and loss of control, quality of life, and wearing comfort) that evaluate the satisfaction of the subject with the wearable part of a system. Each area includes 5 statements rated by the user on a 5point Likert scale between 0 (strongly disagree with the statement) and 4 (strongly agree with the statement). The questionnaire is described in supplemental table S1. In this study, only the benefit, usability, and wearing comfort areas were administered.

\section{Supplemental Appendix S3 Correlation Analysis}

Supplemental tables S2 and S3 showed the results of a correlation analysis performed on the entire sample of patients $(n=37)$ between change scores of primary outcome measures (BBS and gait speed) and age, time since diagnosis, Hoehn and Yahr stage, and baseline score on the UPDRS-III scale. In particular, Spearman correlation coefficients $(\rho)$ and related $P$ values were computed.

It can be noticed from the results that, for both outcome measures, change scores ( $\mathrm{t} 1-\mathrm{t} 0$ and $\mathrm{t} 2-\mathrm{t} 0)$ are not significantly correlated with the selected variables, suggesting that, independently from the received intervention, the improvements attained after rehabilitation are not related to age, disease duration, and disease severity (Hoehn and Yahr stage and UPDRS-III score). 
Supplemental Table S1 Tele-healthcare Satisfaction Questionnaire-Wearable Technology

\begin{tabular}{|c|c|}
\hline Area & Statement \\
\hline Benefit & $\begin{array}{l}\text { 1. I can benefit from this technology } \\
\text { 2. The effort of using this technology/method is worthwhile for me } \\
\text { 3. I am confident I am getting the most out of this technology/method } \\
\text { 4. This technology/method is helping me to achieve my goals } \\
\text { 5. I would recommend this technology/method to other people in my situation }\end{array}$ \\
\hline Usability & $\begin{array}{l}\text { 1. The use of this technology/method requires effort } \\
\text { 2. The technology/method is reliable according to my estimation and experience so far } \\
\text { 3. This technology/method is easy to use } \\
\text { 4. I feel safe when using this technology/method } \\
\text { 5. I feel good while using this technology/method }\end{array}$ \\
\hline Self-concept & $\begin{array}{l}\text { 1. The use of this technology/method is an interesting challenge for me } \\
\text { 2. This technology/method reminds me of losing my independence } \\
\text { 3. The use of this technology/method is making me feel older than I am } \\
\text { 4. I (would) feel embarrassed using this technology/method visible around others } \\
\text { 5. I like to use technologic products or systems like this technology/method }\end{array}$ \\
\hline $\begin{array}{l}\text { Privacy and loss of } \\
\text { control }\end{array}$ & $\begin{array}{l}\text { 1. I feel there is too much supervision by this technology/method } \\
\text { 2. I use this technology/method by request of others (eg, physician, therapist, relatives) } \\
\text { 3. I am sure that my personal data are stored or processed in an appropriate way } \\
\text { 4. The use of this technology/method may have unpredictable negative consequences for me } \\
\text { 5. This technology/method forces me to disclose personal facts that I prefer to keep to myself }\end{array}$ \\
\hline Quality of life & $\begin{array}{l}\text { 1. Using this technology/method improves my physical well-being } \\
\text { 2. This technology/method evokes unpleasant feelings } \\
\text { 3. This technology/method enhances my social contacts } \\
\text { 4. This technology/method helps me to maintain or increase my independence (eg, regarding mobility, } \\
\text { communication, medication) } \\
\text { 5. The use of this technology/method has a positive effect on me }\end{array}$ \\
\hline Wearing comfort & $\begin{array}{l}\text { 1. Wearing this device (parts of the device) is comfortable } \\
\text { 2. I am pleased with the size of the device (parts of the device) } \\
\text { 3. I would wish for another look and design of the device (parts of the device) } \\
\text { 4. I am pleased with the weight of the device (parts of the device) } \\
\text { 5. The body-worn parts of the device are difficult to adjust (fix, fasten) }\end{array}$ \\
\hline
\end{tabular}

Supplemental Table S2 Coefficient of correlation (Spearman $\rho$ ) between change scores ( $\mathrm{t} 1-\mathrm{t} 0$ and $\mathrm{t} 2-\mathrm{t} 0$ ) in BBS and age, time since diagnosis, Hoehn and Yahr stage, and UPDRS-III score for the entire sample $(n=37)$

\begin{tabular}{lrrrrrr}
\hline & \multicolumn{2}{c}{$\begin{array}{c}\text { BBS Change } \\
\text { Score (t1-t0) }\end{array}$} & & \multicolumn{2}{c}{$\begin{array}{c}\text { BBS Change } \\
\text { Score (t2-t0) }\end{array}$} \\
\cline { 2 - 3 } Independent Variable & $\rho$ & $P$ & & $\rho$ & $P$ \\
\hline Age & -.082 & .630 & & -.039 & .818 \\
Time since diagnosis & -.152 & .369 & & -.191 & .254 \\
Hoehn and Yahr stage & .141 & .406 & & -.017 & .921 \\
UPDRS-III baseline score & .099 & .558 & & -.061 & .721 \\
\hline
\end{tabular}

Supplemental Table S3 Coefficient of correlation (Spearman $\rho$ ) between change scores ( $\mathrm{t} 1-\mathrm{t} 0$ and $\mathrm{t} 2-\mathrm{t} 0$ ) in gait speed and age, time since diagnosis, Hoehn and Yahr stage, and UPDRS-III score for the entire sample $(n=37)$

\begin{tabular}{|c|c|c|c|c|}
\hline \multirow[b]{2}{*}{ Independent Variable } & \multicolumn{2}{|c|}{$\begin{array}{l}\text { Gait Speed } \\
\text { Change Score } \\
(\mathrm{t} 1-\mathrm{t} 0)\end{array}$} & \multicolumn{2}{|c|}{$\begin{array}{c}\text { Gait Speed } \\
\text { Change Score } \\
\text { (t2-t0) }\end{array}$} \\
\hline & $\rho$ & $P$ & $\rho$ & $P$ \\
\hline Age & .074 & .664 & -.113 & .505 \\
\hline Time since diagnosis & .140 & .407 & .089 & .600 \\
\hline Hoehn and Yahr stage & -.005 & .977 & -.206 & .222 \\
\hline UPDRS-III baseline score & -.031 & .857 & -.119 & .482 \\
\hline
\end{tabular}

